\title{
An improved reservoir for the flushing test to diagnose shunt insufficiency
}

\author{
Hans-Georg Schlosser, MD, ${ }^{1,3}$ Hans-Joachim Crawack, PhD, ${ }^{2}$ Christoph Miethke, Dipl-Ing, ${ }^{2}$ \\ Thoralf Knitter, Dipl-Ing, ${ }^{2}$ Andreas Zeiner, MD, ${ }^{1,3}$ and Christian Sprung, MD ${ }^{1}$
}

\begin{abstract}
${ }^{1}$ Department of Neurosurgery, Universitätsmedizin Berlin - Charité, Berlin; ${ }^{2}$ Christoph Miethke GmbH, Potsdam; and ${ }^{3}$ Gutachten Neurochirurgie, Wirbelsäule, und Physiologie (NWP), Berlin, Germany
\end{abstract}

\begin{abstract}
OBJECTIVE Reservoirs integrated into hydrocephalus shunts are commonly used for the removal of CSF and for intraventricular pressure measurement. Pumping with the reservoir to diagnose shunt sufficiency is still a matter of controversy. The authors describe an improved flushing device and its characteristic features in vitro and in vivo.

METHODS The flushing reservoir is constructed with a sapphire ball in a cage as a nonresistance valve to also enable the detection of distal occlusions. The most important reservoir parameters were investigated in vitro, simulating total and partial proximal and distal shunt occlusions. Then the expected advantages were assessed in vivo by evaluating the pump test data of 360 implanted reservoirs. The results were compared with those found in the literature.

RESULTS The optimization of the technical parameters of the device, such as the high stroke volume in combination with moderate suction force, are obvious advantages compared with other flushing devices. Total occlusion of the ventricular catheter and the valve could be assessed with high certainty. The detection of a total obstruction of the peritoneal catheter or any partial obstruction is also possible, depending on its exact grade and location.
\end{abstract}

CONCLUSIONS Shunt obstructions can be assessed using the pumping test. The reservoir construction presented here provides a clear enhancement of that diagnostic test.

http://thejns.org/doi/abs/10.3171/2016.6.FOCUS15540

KEY WORDS shunt reservoir; diagnostic flushing test; hydrocephalus; shunt insufficiency

$\mathrm{T}$ HE benefit of shunt-integrated reservoirs for the treatment of hydrocephalus, cysts, or other pouches is generally accepted, and numerous designs are already available on the market. $5,6,8,14,19,21,22,25,26,28-30,32,33$ The types include bore-hole or inline reservoirs (prechambers or integrated into the valve). By puncturing the reservoir intracranial pressure can be measured, or CSF can be removed in case a rapid decompression is required. If an infection is suspected, CSF composition can be analyzed and medications or contrast media and so on can be injected into the ventricles. Since the early days of shunt technology, the valve was also used for pumping (or synonymously flushing) to control the shunt function. ${ }^{4,20}$ Likewise, pumping was considered to be a useful means for carefully removing shunt occlusions. ${ }^{4}$ According to our broad clinical experience, flushing is nowadays in worldwide use for testing shunt sufficiency. However, in our opinion this widespread practice is not really reflected in the literature. On the contrary, the majority of the authors still doubt the usefulness of this basic test. . $^{1,6,610,13,22,25-27,31-33}$

We describe the optimization of a pumping device, and we present the comprehensive clinical data we collected. Furthermore, we examined whether negative findings in the literature are possibly based to a large extent on the use of suboptimal reservoirs, combined with uncertainties in their study design.

\section{Methods}

\section{Reservoir Construction}

Figure 1 shows the construction of the reservoir (Aesculap/Miethke). It can be used in combination with any valve type. For the pumping test, the silicone dome of the implanted device is compressed with a finger, and after-

ABBREVIATIONS $\mathrm{dPC}=$ distal peritoneal catheter; $\mathrm{dVC}=$ distal ventricular catheter; $\mathrm{pPC}=$ proximal peritoneal catheter; $\mathrm{pVC}=$ proximal ventricular catheter; $\mathrm{VP}=$ ventriculoperitoneal. 


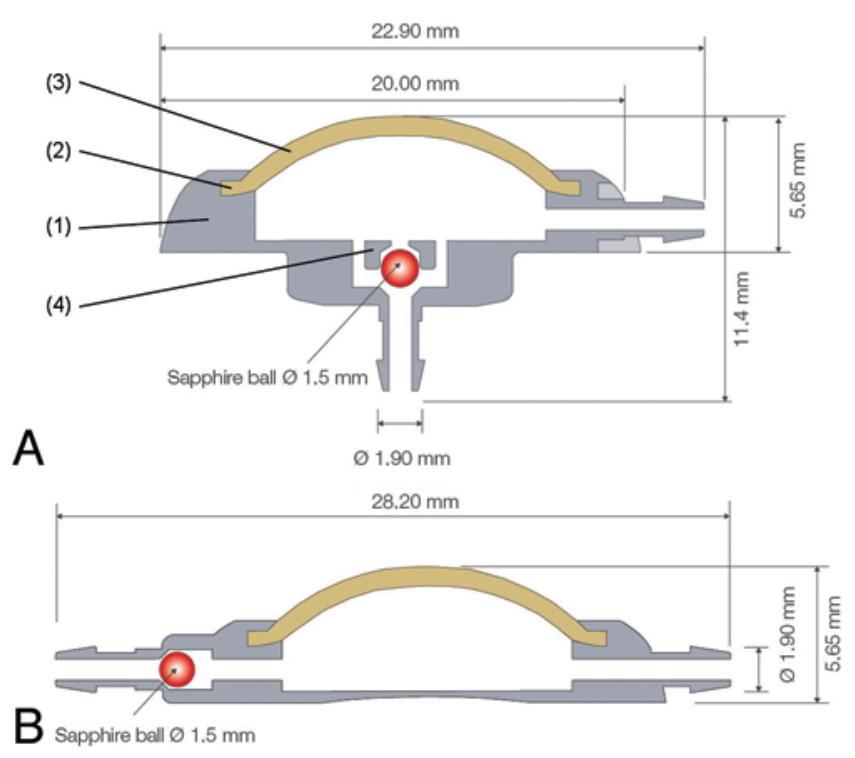

FIG. 1. Images of the new flushing device as a bore-hole reservoir ("Sprung reservoir"; A) and as an inline reservoir ("control reservoir"; B). In the titanium housing (1), a disc of silicone is pressed into a groove (2), forming a clear transparent dome (3). In the proximal inlet of this reservoir, a loose sapphire ball is trapped in a cage (4). $\varnothing=$ diameter.

ward it reinflates automatically. In contrast to other reservoirs, the new device is characterized by the following unique features:

- In the proximal reservoir inlet, a loose sapphire ball is integrated, which acts like a nonresistance valve. In case of fast dome compression, this ball closes the device proximally. This mechanism ensures that the CSF moves only in the distal direction toward the shunt valve and the peritoneum. In this way, distal occlusions can also be detected.

- The dome is safely sealed by impressing a silicone disc into a groove. The titanium bottom cannot be destroyed by puncturing. Thus, there is also no leakage subsequent to multiple punctures.

- The transparency of the dome allows control of CSF flow through the reservoir during implantation. Any debris, blood clots, and obstructing air bubbles can be seen and removed intraoperatively by pumping. With a final flushing directly before inserting the tip of the peritoneal catheter into the abdominal cavity, any insufficiency in the entire system by kinking or clotting can be ruled out.

- The reservoir location is intentionally chosen distant from the valve to allow easier localization and to avoid the danger of damage to the valve mechanism by puncturing or pumping.

We propose that the technical performance of any reservoir may be characterized by 4 parameters: a) number of strokes per milliliter; $b$ ) force required to compress the (empty) dome; c) emerging proximal suction (i.e., negative pressure) during automatic dome reinflation; and d) overall flow resistance. The maximal pressure producible depends on the compression force applied. In contrast, the proximal suction (c, just mentioned) is a fixed technical parameter exclusively dependent on the silicone dome's properties. Other technical aspects for characterization are outer form and long-term behavior. The 4 parameters (a-d) will be discussed because they are the most important ones.

For further pumping test optimization, the number of strokes per milliliter, the dome compression force, and the extra flow resistance must be minimized. Also the suction created must not be too high, to avoid the danger of sucking brain parenchyma, choroid plexus, or any other tissue into the ventricular catheter.

Table 1 provides an overview of parameters a-c discussed above for some reservoirs and valves on the market, adopted from the work of Aschoff. ${ }^{1}$ One should be aware that, in contrast to the valves, all the conventional reservoirs and prechambers measured here are not specifically constructed for flushing, and can only be used for the diagnosis of occlusion of the proximal ventricular catheter in combination with unidirectional valves. The standard deviations of the average values are extremely high. The comparison of these average values with those for the reservoir presented here (last row in Table 1) shows the desired improvement for the categories "strokes/ml" and "dome compression force." The suction created during reinflation of the modified reservoir remains in the middle range.

The small additional opening pressure for the new reservoir measured in vitro turned out to be slightly dependent on its orientation in space, because of the low weight of the sapphire ball. Also, with the device in the upright position, when the sapphire ball in the cage is pulled down to the valve seat, the additional opening pressure does not exceed $1 \mathrm{~cm} \mathrm{H}_{2} \mathrm{O}$ and is therefore negligible.

\section{Flushing Test Operational Sequence}

Although it may be trivial for any experienced neurosurgeon, to avoid any confusion in Fig. 2 the various parts of a ventriculoperitoneal (VP) shunt are defined once

TABLE 1. Comparison of characteristic parameters of the most common devices with those of the Sprung reservoir

\begin{tabular}{lccc}
\hline Type of Reservoir or Valve & $\begin{array}{c}\text { No. of } \\
\text { Strokes for } \\
\text { the Pumping } \\
\text { of } 1 \mathrm{ml}\end{array}$ & $\begin{array}{c}\text { Dome } \\
\text { Compression } \\
\text { Force }(\mathrm{g})\end{array}$ & $\begin{array}{c}\text { Suction } \\
\text { After 1 } \\
\text { Stroke } \\
(\mathrm{mm} \mathrm{Hg})\end{array}$ \\
\hline Ommaya reservoir & 2.0 & 180 & -75 \\
\hline Rickham reservoir & 5.4 & 420 & -60 \\
\hline Selker reservoir & 3.3 & 500 & -105 \\
\hline Hakim-Cordis prechamber & 7.0 & 700 & -75 \\
\hline Spitz-Holter cylindrical & 8.8 & 410 & -60 \\
\hline Heyer-Schulte standard & 14.0 & 420 & -75 \\
\hline PS Medical CSF flow & 3.7 & 335 & -150 \\
\hline PS Medical "Delta" & 3.0 & 390 & -135 \\
\hline Hakim-Cordis valve & 11.0 & 280 & -60 \\
\hline Medos-Hakim valve & 6.1 & 160 & -60 \\
\hline Average \pm SD & $6.4 \pm 3.9$ & $380 \pm 149$ & $-86 \pm 31$ \\
\hline Sprung/control reservoir* & 3.6 & 320 & -88 \\
\hline * Described in this article & & &
\end{tabular}

* Described in this article. 


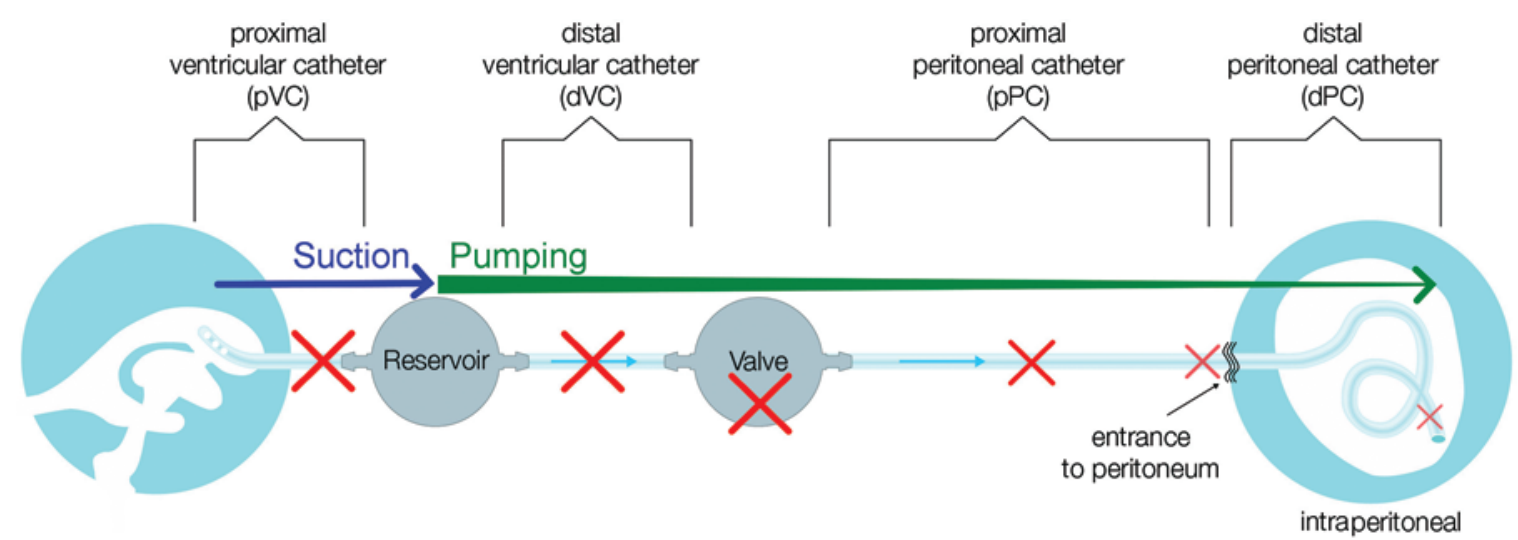

FIG. 2. Drawings showing definitions of the various parts of a VP shunt and the locations of the respective occlusions. By dome compression (pumping), the ball closes the inlet of the reservoir and produces a distal flow, while the automatic dome reinflation creates a suction to the ventricles. The test validity depends on the distance between the reservoir and the occlusion, indicated by the size of the red occlusion crosses.

again: the terms "ventricular" and "peritoneal" refer to the catheter position always relative to the valve, but "proximal" and "distal" refer to the distance from the ventricle relative to the valve or the reservoir, respectively.

The 3 results of the pumping test illustrated above are differentiated and interpreted as follows:

1. Negative ("normal"): dome is easy to compress with moderate force and it subsequently reinflates quickly ( $\leq$ 1 second); this means that the shunt is working properly, no occlusion.

2. Positive ("not-normal"): dome is easy to compress with moderate force, but afterward it reinflates either a) not at all or b) only slowly (>1 second); this is a sign for suspicion of either a) a full or b) a partial obstruction of the proximal ventricular catheter (pVC).

3. Positive ("not-normal"): dome is either a) not compressible or b) it is only hard to compress; this is a sign for or suspicion of either a) a total or b) a partial obstruction of the distal ventricular catheter (dVC), proximal peritoneal catheter ( $\mathrm{pPC})$, or distal peritoneal catheter (dPC).

Figure 3 illustrates the flushing test procedure in accordance with the 3 different possible test results explained above or the 3 different states of the shunt, respectively: 1) shunt unoccluded; 2) proximally occluded; or 3) distally (partially or fully) occluded.

\section{Patients and Clinical Data}

Between 2004 and 2009 we implanted 353 VP shunts with the frontal bore-hole reservoir in combination with a Miethke proGAV as a consecutive series, and 7 inline reservoirs were inserted as a prechamber. Thus, a total of 360 patients were examined in this study, with a follow-up duration of at least 5 years. All patients were adolescents or adults suffering from hydrocephalus.

In all cases radiographs and a CT scan were performed and the function of the shunt was ensured by a negative result on the pumping test before patient discharge. Afterward every patient was reevaluated routinely every year in the outpatient department. In cases of clinical deterioration and suspected dysfunction, we repeated the pumping test and the radiological examinations (radiography, CT, or MRI).

\section{Results \\ In Vitro Results}

The most important results of our own in vitro experiments are displayed in Fig. 4. The graph on the left-hand side (Fig. 4A) is related to Test Case 2 (see also Fig. 3, Test Case 2): it shows the dome reinflation time depending on the grade of the partial obstruction of the pVC. It is directly derived from Hagen-Poiseuille's law, with the simplified assumption of a constant suction of $-88 \mathrm{~mm} \mathrm{Hg}$ created by the dome reinflation and an accompanying constant volume flow of $0.28 \mathrm{ml} /$ reinflation time (Table 1). The graph was experimentally calibrated by measuring the reservoir reinflation time (see the single calibration point, marked with the blue arrow) with a calibration tube of known length and flow diameter, which was a standard syringe needle of $2.5-\mathrm{cm}$ length and $0.275-\mathrm{mm}$ inner diameter. According to Hagen-Poiseuille's law, the dome reinflation time depends heavily on the grade of the occlusion; i.e., mainly on the remaining free flow diameter but also on the occlusion length. An open proximal standard catheter with a normal inner diameter of $1.2 \mathrm{~mm}$ does not cause any noticeable increase of the reservoir reinflation time up to 8 $\mathrm{m}$ in length (see Fig. 4A, red line); a conventional ventricular catheter with only 1 hole open $(0.5 \mathrm{~mm})$ would need an obstruction length of more than $6 \mathrm{~cm}$ to increase the reinflation time above 1 second (see Fig. 4A, green line). However, in summary, any reservoir reinflation time up to several minutes could be provoked with this experimental setting if the free flow diameter of the simulated partially obstructed (i.e., narrowed) pathway is small enough, or the obstruction length is long enough, respectively.

Figure 4 shows the experimental setting (panel B) and the results (panel C) for the simulation of a full distal obstruction depending on the distance between the reservoir and the obstruction. This in vitro experiment is related to Test Case 3 (see also Fig. 3, Test Case 3): if the dVC directly behind the reservoir is fully obstructed it would not 


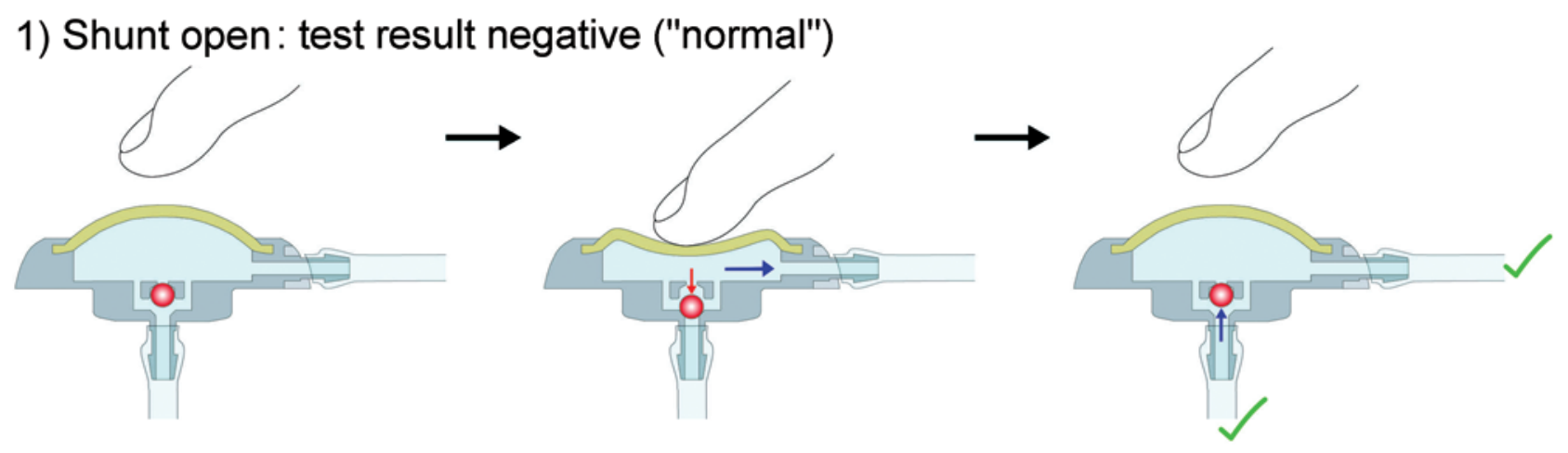

2) Shunt proximally occluded: test result positive ("not-normal")

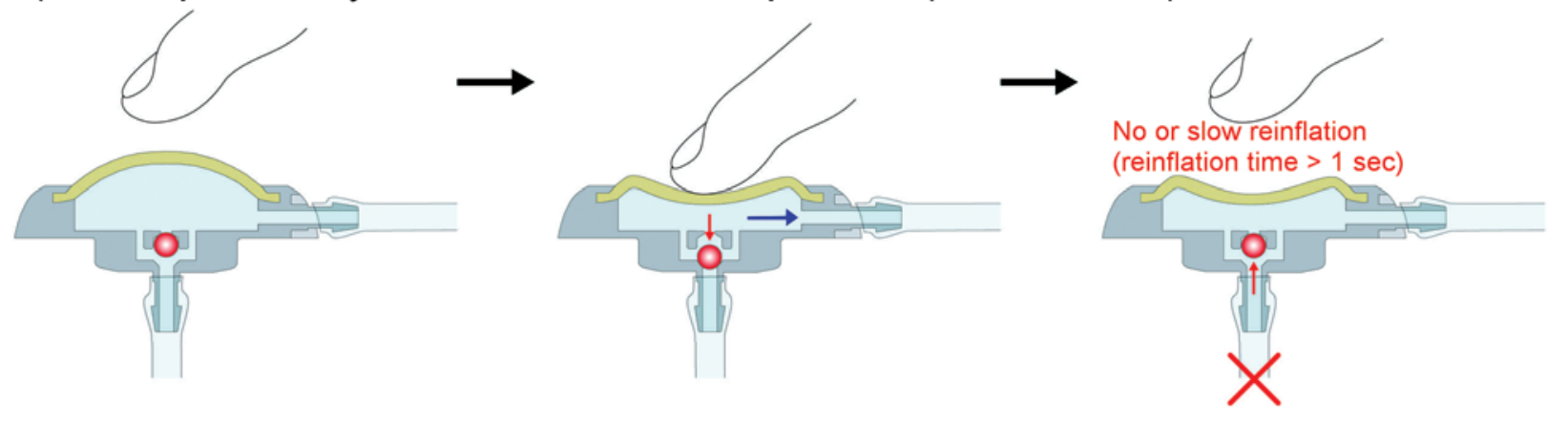

3) Shunt distally occluded: test result positive ("not-normal")

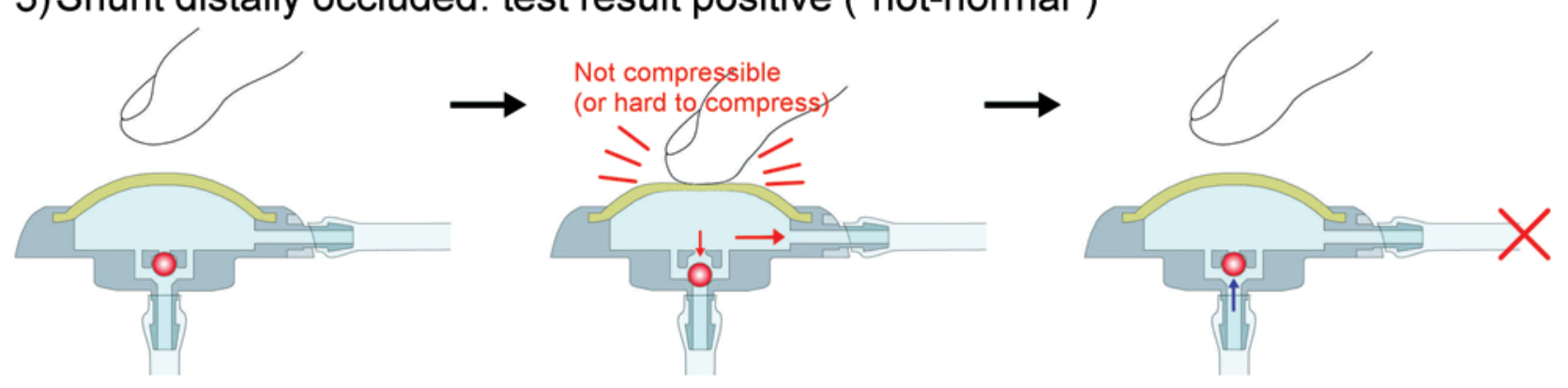

FIG. 3. Drawings showing the operational sequence of the flushing test in accordance with the 3 possible states of the shunt: 1) open; 2) proximally occluded; or 3) distally (partially or fully) occluded.

be possible to pump or to compress the dome at all, and the resulting diagnosis is unequivocal. On the other hand, if the catheter is open the dome is easily compressedapproximately $5 \mathrm{~mm}$-down to the bottom (see Fig. 4C, green and purple lines). If the obstruction is more distant to the reservoir, a slight impression with a certain impression depth is possible due to the elasticity of the remaining free silicone tube. The catheter behaves like a balloon that can be partly inflated. As can be seen in Fig. 4C (red and blue lines), in the worst case scenario that the occlusion is located $1 \mathrm{~m}$ from the reservoir (i.e., at the end of the peritoneal catheter in the peritoneum), the remaining impression depth is still approximately $50 \%$ of that in the case of an open catheter.

\section{Clinical Results}

Already in 1996 Drake pointed out that for all diagnostic shunt function tests, a practicable noninvasive gold-standard method was lacking. ${ }^{10}$ This is the com- mon problem for everybody working in the field of hydrocephalus shunts. Therefore, here we describe how to determine the shunt function with increasing reliability. In general this weakness is circumvented by the pragmatic and plausible assumption that the shunt is functioning well when the ventricular size is normal or unchanged and the clinical status of the patient is good at the time point of the pumping test and 6 months thereafter, so that no revision is required. The same applies when symptoms of underdrainage or overdrainage could be relieved simply by valve adjustments. ${ }^{34}$ Of course this pragmatic approach might lead to one overlooking some false-negative test results; i.e., cases in which the patient is well although the shunt is working insufficiently. Also, as stated by other authors,${ }^{30}$ we cannot rule out any cases of so-called arrested hydrocephalus with the combination of dilated ventricles and good clinical status in spite of an occluded shunt. However, it is likely that these numbers are very small. The clinical courses of the individual cases will have to be discussed elsewhere. 

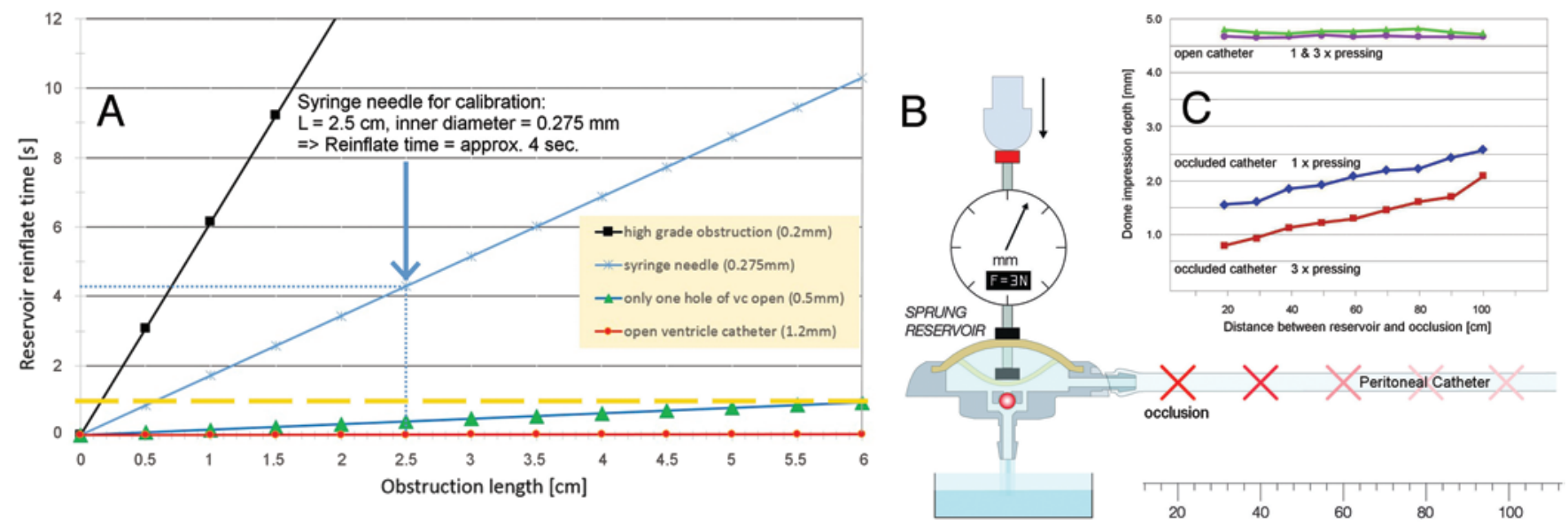

FIG. 4. A: Graph showing reservoir reinflation time depending on the length and the remaining open diameter of a partial pVC obstruction. Note that a significant reduction of the inner flow diameter is necessary to result in a noticeable prolongation of the dome reinflation time of $>1$ second (yellow line). B: Image of an in vitro device for measuring the force and depth of compression. C: Graph showing the measured depth of the dome impression depending on the distance to the distal occlusion and the number of pumping/pressing maneuvers: full impression depth of the dome is only achieved when the catheter is unoccluded (green and purple lines).

The results of our clinical flushing tests are presented in Table 2. In all the cases presented here we experienced only 3 surgical/mechanical complications due to the reservoir: 2 cases of superficial wound healing problems and 1 occlusion of the device itself.

\section{Discussion}

Various invasive diagnostic test procedures for the verification of shunt function have been described: invasive CSF pressure ${ }^{15}$ and flow measurements, ${ }^{17,18}$ CSF tap test and drip interval test, ${ }^{32,33}$ infusion tests,, 24 and radioactive shuntogram. ${ }^{23,35}$ By comparison, publications addressing the noninvasive pumping test are rare. Table 3 presents an overview of the literature on the noninvasive pumping test from 1977 to 2003.

The results published in the quoted literature (Table 3) are in clear contradiction to our own findings, based on pumping tests performed with the Sprung/control reservoir discussed here. In contrast to our data, all formerly published results are values derived from tests with a variety of reservoirs and valves (at least 2 types). In a few reports, the shunt/reservoir type used is not even specified, although the technical parameters of such reservoirs and valves are obviously essential. ${ }^{11}$ To judge occlusions distally from the reservoir (i.e., dVC, pPC, and $\mathrm{dPC}$ ), other authors have had to close the pVC transcutaneously by manual compression. ${ }^{22,25,26}$ In our opinion this is never possible with a sufficient certainty and, if ever undertaken, it usually does provide a source of error. In contrast, with the reservoir discussed here the proximal closure is always safely and automatically performed with the additional ball-in-cage mechanism. Furthermore, the earlier studies deal with smaller case numbers in comparison with our series of 360 patients.

The evaluated historical patient groups consisted mostly of children or infants, whereas our own data are based on adults older than 18 years. Compared with other authors $^{16,19}$ we had fewer mechanical complications, and notably no migrations or disconnections. Our series did not comprise pediatric patients with hydrocephalus, who

TABLE 2. Results of all 360 flushing tests in correlation with the actual or assumed sufficiency of the proximal or distal ventricular or peritoneal catheter*

\begin{tabular}{|c|c|c|c|c|}
\hline \multirow[b]{2}{*}{ Flushing Test Result } & \multicolumn{4}{|c|}{ Probable Shunt Status } \\
\hline & \multicolumn{2}{|l|}{ Total or Partial Occlusion† } & \multicolumn{2}{|c|}{ No Occlusion $\ddagger$} \\
\hline \multicolumn{5}{|l|}{ Not normal/positive } \\
\hline Not reinflating & pVC total occlusion (5 cases) & \multirow{4}{*}{ Subtotal 11} & 0 & \multirow{4}{*}{ Subtotal 11} \\
\hline Slowly reinflating; $>1 \mathrm{sec}$ & pVC partial occlusion (1 case) & & 11 cases & \\
\hline Not compressible & Reservoir/dVC/dPC total occlusion ( 3 cases) & & 0 & \\
\hline Hard to compress & Reservoir/dVC/dPC partial occlusion (2 cases) & & 0 & \\
\hline Normal/negative & dPC partial occlusion ( 3 cases) & & 335 & \\
\hline Total & 14 & & 346 & \\
\hline
\end{tabular}


TABLE 3. Comparison of the results in the literature concerning the reliability of the flushing test for the diagnosis of shunt sufficiency

\begin{tabular}{|c|c|c|c|}
\hline Authors \& Year & Test/Shunt Type & Cases/Patients & Authors' Conclusions/Remarks \\
\hline \multirow[t]{3}{*}{$\begin{array}{l}\text { Osaka et al., } \\
1977\end{array}$} & Pumping & $\begin{array}{l}97 \text { operations; } 47 \text { shunts } \\
\quad \& 50 \text { revisions }\end{array}$ & $\begin{array}{l}\text { "Accordingly, we conclude that the flushing device is a very poor } \\
\text { indicator of shunt functioning." }\end{array}$ \\
\hline & Single- \& double-Iumen Pudenz & & \\
\hline & & Children & $\begin{array}{l}\text { No regular statistical evaluation. For } 16 \text { of } 97 \text { cases, no flushing } \\
\text { device or no information regarding the device is available; } 6 \\
\text { are missing. }\end{array}$ \\
\hline $\begin{array}{l}\text { Kaiser \& Mini- } \\
\quad \text { kus, } 1984\end{array}$ & $\begin{array}{l}\text { Pumping only mentioned by a casual } \\
\text { remark; CSF pressure measurement } \\
\text { was evaluated as a diagnostic test }\end{array}$ & $\begin{array}{l}72 \text { pressure measure- } \\
\text { ments } \\
65 \text { children }\end{array}$ & $\begin{array}{l}\text { "A palpable normal valve function can be observed in every } \\
\text { category of shunt patient;" "There was no relation between } \\
\text { the individual palpable valve function and the height of CSF } \\
\text { pressure." }\end{array}$ \\
\hline
\end{tabular}

Shunt type not specified

Incomplete/unclear data; 7 are missing.

Piatt, $1992 \quad$ Pumping 200 patients; 493 tests Pumping test is unsuitable.

\begin{tabular}{|c|c|c|c|}
\hline & $\begin{array}{l}\text { Variety of different shunt valves } \\
\text { encountered }\end{array}$ & $\begin{array}{l}\text { Mixed patients: } 1 \text { mo-28 } \\
\text { yrs, median } 7 \text { yrs }\end{array}$ & \\
\hline $\begin{array}{c}\text { Sood et al., } \\
1993\end{array}$ & $\begin{array}{l}\text { Pumping only mentioned by a casual } \\
\text { remark; originally tap test was evalu- } \\
\text { ated as a diagnostic test }\end{array}$ & $\begin{array}{l}\text { At least } 19 \text { pumped } \\
\text { Infants \& children }\end{array}$ & $79 \%$ of 19 correctly diagnosed by pumping. \\
\hline
\end{tabular}

Low-pressure \& medium-pressure valves, PS Medical

\begin{tabular}{|c|c|c|c|}
\hline $\begin{array}{l}\text { Aschoff et } \\
\text { al., 1994; } \\
\text { Aschoff et } \\
\text { al., } 2003\end{array}$ & $\begin{array}{l}\text { Pumping } \\
\text { Huge variety of different shunt valves }\end{array}$ & $\begin{array}{l}\text { In vitro experiments } \\
\text { No patients }\end{array}$ & $\begin{array}{l}\text { "Pumping is unable to identify any partial occlusions and most } \\
\text { distal occlusions. Identification of complete proximal occlu- } \\
\text { sion was reliable, but there is a risk for sucking plexus or } \\
\text { ependymal." }\end{array}$ \\
\hline $\begin{array}{l}\text { Piatt et al., } \\
1996\end{array}$ & $\begin{array}{l}\text { Pumping } \\
\text { Variety of different shunt valves } \\
\text { encountered }\end{array}$ & $\begin{array}{l}114 \text { longitudinal: } 2 x \\
\text { compressing } \\
\text { Pediatric }\end{array}$ & $\begin{array}{l}\text { "Test not sensitive enough;" "Uncertain as the flip of a coin;" } \\
\text { "Interval shunt pumping test not useful in the hands of a } \\
\text { paediatric neurosurgeon." }\end{array}$ \\
\hline Present study & $\begin{array}{l}\text { Pumping } \\
\text { Sprung/control reservoir \& proGAV }\end{array}$ & $\begin{array}{l}360 \\
\text { Adults }>18 \text { yrs }\end{array}$ & $\begin{array}{l}\text { In vitro and in vivo tests w/ the new reservoir prove reliability } \\
\text { of flushing test as a diagnostic procedure for assessment of } \\
\text { shunt function. }\end{array}$ \\
\hline
\end{tabular}

No case w/ proximal occlusion after pumping because of suction.

have a higher susceptibility for these complications due to growth and more delicate skin. It is well known that children have a higher complication rate than adults, and are less compliant to the pumping maneuver. ${ }^{26}$ Therefore a comparison of our series with groups of children and adolescents must be done cautiously, and this is only possible with limitations.

Aschoff confirmed that the pumping test is able to diagnose total proximal occlusions and also, in $40 \%$ of the devices, total distal occlusions. But he doubted the possibility of diagnosing partial obstructions, because he assumed that this has no visible/palpable influence on the reaction of the silicone dome..$^{1-3}$ He derived this conclusion from in vitro experiments where the partial obstruction of the $\mathrm{pVC}$ was simulated by a series of differential pressure valves. However, his experimental setting was inadequate, because binary (on-off) differential pressure valves are not suited to simulate an increase of flow resistance. We demonstrated in our own in vitro experiments as presented in Fig. 4A that any prolonged reinflation time up to several minutes can be achieved if the partial proximal occlusion is sufficient (i.e., if the remaining flow diameter is small and the occlusion length is long enough). In fact, also in the clinical series presented here, this characteristic behavior of the reservoir dome was sometimes visible or palpable, although the effect was attenuated by the skin covering the dome. According to our experience, for such a diagnosis a prolonged reinflation time of at least 1 second (see Fig. 4A, yellow horizontal line) is needed to distinguish a partial obstruction from the normal status.

Clinically, the smaller the remaining open diameter of the $\mathrm{pVC}$, the longer an existing elevated intraventricular pressure needs to be relieved by CSF flow through the obstructed catheter. We believe that each patient reacts differently in this characteristically prolonged so-called overpressure relief time. Thus, unfortunately, the very important clinical question: "Which degree of partial pVC obstruction finally requires a shunt revision?" cannot be answered definitely.

With the reservoir described here, an occlusion of the 
$\mathrm{dVC}$ or the valve is easy to diagnose in case the compression resistance is very high (see Fig. 3, Test Case 3). Our own in vitro experiments as presented in Fig. 4B and $\mathrm{C}$ demonstrated that due to the elasticity of the silicone catheter, even in the case of full distal obstruction of the peritoneal catheter, some considerable impression of the dome is possible: for the maximal distance of $1 \mathrm{~m}$ between reservoir and occlusion, the impression depth is approximately $50 \%$ of that in the case of an open catheter. In our in vitro experiments, a $50 \%$ impression depth can easily be distinguished from the full impression down to the bottom of the reservoir. Therefore, such a clear difference in vitro should be palpable also in vivo. However, even when simulating the in vivo conditions by overlaying the reservoir with a skin-like cover, it ended up being difficult to always arrive at a significant conclusion.

In summary, the possibility of detecting any partial occlusion by pumping is greater, the higher the grade of obstruction, the shorter the distance between reservoir and obstruction, and the more experienced the examiner is in comparing the test results.

The danger of sucking brain parenchyma or any other tissue into the pVC has often been emphasized. ${ }^{1-3}$ We never saw any clinical symptoms of relevant hypotension following pumping, 1,6,7,11 or radiological signs of overdrainage or hemorrhage. ${ }^{12}$ We still cannot fully exclude such a danger, especially in cases involving very narrow ventricles. Thus we also recommend that the practitioner avoid unnecessary flushing, or at least confine it to a minimum number of strokes. ${ }^{6}$ Furthermore, in contrast to the findings of Piatt, ${ }^{26}$ it turned out to be important not to judge only a single pumping test result, but also to assess any changes during the follow-up.

\section{Conclusions}

To our knowledge, this is the first systematic in vitro and in vivo study of a flushing device. Several parameters of the device, such as high stroke volume, ease of dome compression, moderate suction pressure, simplicity of localization for puncturing, and transparency of the dome, are obvious advantages when compared with other reservoirs. In a clinical series of 360 adult patients with hydrocephalus, it is demonstrated here that pumping with this reservoir is a valid diagnostic test to assess shunt insufficiency. Total occlusion of the ventricular catheter can be diagnosed reliably. Also, the detection of total occlusions of the peritoneal catheter is made possible by the construction principle, including a significantly higher stroke volume and impression depth of the reservoir.

We have pointed out that this remarkable improvement in pumping test quality is a result of the modified reservoir design together with the strict study design (i.e., usage of a clearly characterized reservoir with only 1 valve, and unequivocal definitions of positive/negative test results). Nevertheless, any pumping test must always be one criterion among others on which a decision for a shunt revision will be based; it must always be set in relation to clinical status and radiological findings. On the basis of our results with the described improved reservoir, we believe in a reappraisal of the pumping function.

\section{Acknowledgments}

Our colleague Dr. Christian Sprung died before this paper could be published. His scientific life was dedicated to hydrocephalus research. We miss Christian and the vivid discussions filled with his profound experience.

\section{References}

1. Aschoff A: In-vitro-Testung von Hydrocephalus-Ventilen [dissertation]. Heidelberg: Ruprecht-Karls-University, 1994, pp 179-189

2. Aschoff A, Hashemi B, Kunze P, Kremer P: The reliability of palpatoric shunt checks. An in vitro study, in 54th Annual Meeting of the German Society of Neurosurgery. Berlin: Deutsche Gesellschaft für Neurochirurgie, 2003 (Abstract) (http://www.dgnc.de/dgnc03/pdf/abstract/mo_08.pdf) [Accessed August 1, 2016]

3. Aschoff A, Klank A, Benesch C, Fruh K: Shunt function control by valve pumping - fact or fancy? In-vitro-studies for the reliability, limitations and side-effects of palpatoric shunt checks, in Proceedings of the 14th Congress of the European Society for Pediatric Neurosurgery. Cham, Switzerland: Springer, 1994

4. Baru JS, Bloom DA, Muraszko K, Koop CE: John Holter's shunt. J Am Coll Surg 192:79-85, 2001

5. Bondurant CP Jr, Overton MC III, Coe JE: The puncturable ventriculo-atrial shunt for hydrocephalus. A preliminary report. Acta Neurochir (Wien) 13:544-555, 1965

6. Bromby A, Czosnyka Z, Allin D, Richards HK, Pickard JD, Czosnyka M: Laboratory study on "intracranial hypotension" created by pumping the chamber of a hydrocephalus shunt. Cerebrospinal Fluid Res 4:2, 2007

7. Chari A, Czosnyka M, Richards HK, Pickard JD, Czosnyka $\mathrm{ZH}$ : Hydrocephalus shunt technology: 20 years of experience from the Cambridge Shunt Evaluation Laboratory. J Neurosurg 120:697-707, 2014

8. Coe JE, Rivet JR, Hargest TS: Twin reservoir flushing device for hydrocephalus. Technical note. J Neurosurg 28:85-86, 1968

9. Czosnyka ZH, Czosnyka M, Pickard JD: Shunt testing in-vivo: a method based on the data from the UK shunt evaluation laboratory. Acta Neurochir Suppl 81:27-30, 2002

10. Drake J: Editorial comment. Pediatr Neurosurg 25:76, 1996

11. Hafez MA, Kempski O: A nonlinear biomechanical model for evaluation of cerebrospinal fluid shunt systems. Childs Nerv Syst 10:302-311, 1994

12. Huang CY, Hung YC, Tai SH, Lee EJ: Cerebellar hemorrhage after multiple manual pumping tests of a ventriculoperitoneal shunt: a case report. Kaohsiung J Med Sci 25:29-33, 2009

13. Humphreys RP: Editorial comment. Pediatr Neurosurg 25:77, 1996

14. James HE, Bruce DA: Ventriculoperitoneal shunts for hydrocephalus: a focus group discussion on the selection of shunt systems in pediatrics. A report of the Pediatric Neurosurgery Research Group meeting, December 1992. Childs Nerv Syst 11:449-452, 1995

15. Kaiser G, Minikus H: The significance of continuous CSF measurement in suspected shunt dysfunction. Eur J Pediatr Surg 39:25-26, 1984

16. Liesegang J, Strahl EW, Streicher HR: Complications following shunt operations in children, in Grote W, Brock M, Clar HE, et al (eds): Surgery of Cervical Myelopathy. Berlin: Springer, 1980, Vol 8, pp 222-226

17. Madsen JR, Abazi GS, Fleming L, Proctor M, Grondin R, Magge S, et al: Evaluation of the ShuntCheck noninvasive thermal technique for shunt flow detection in hydrocephalic patients. Neurosurgery 68:198-205, 2011

18. Maeda T, Mori H, Hisada K, Kadoya S: Evaluation of cerebrospinal fluid flow through a Pudenz $12 \mathrm{~mm}$ or a standard 
Rickham reservoir: phantom experiments. Invest Radiol 12:555-558, 1977

19. Martinez-Lage JF, Poza M, Esteban JA: Mechanical complications of the reservoirs and flushing devices in ventricular shunt systems. Br J Neurosurg 6:321-325, 1992

20. Nulsen FE, Spitz EB: Treatment of hydrocephalus by direct shunt from ventricle to jugular vain. Surg Forum 1951:399403, 1951

21. Ommaya AK: Subcutaneous reservoir and pump for sterile access to ventricular cerebrospinal fluid. Lancet 2:983-984, 1963

22. Osaka K, Yamasaki S, Hirayama A, Sato N, Ohi Y: Correlation of the response of the flushing device to compression with the clinical picture in the evaluation of the functional status of the shunting system. Childs Brain 3:25-30, 1977

23. Ouellette D, Lynch T, Bruder E, Everson E, Joubert G, Seabrook JA, et al: Additive value of nuclear medicine shuntograms to computed tomography for suspected cerebrospinal fluid shunt obstruction in the pediatric emergency department. Pediatr Emerg Care 25:827-830, 2009

24. Petrella G, Czosnyka M, Smielewski P, Allin D, Guazzo EP, Pickard JD, et al: In vivo assessment of hydrocephalus shunt. Acta Neurol Scand 120:317-323, 2009

25. Piatt JH Jr: Physical examination of patients with cerebrospinal fluid shunts: is there useful information in pumping the shunt? Pediatrics 89:470-473, 1992

26. Piatt JH Jr: Pumping the shunt revisited. A longitudinal study. Pediatr Neurosurg 25:73-77, 1996

27. Pople IK: Hydrocephalus and shunts: what the neurologist should know. J Neurol Neurosurg Psychiatry 73 (Suppl 1): $i 17-i 22,2002$

28. Raimondi AJ: Hydrocephalus, in Raimondi AJ (ed): Pediatric Neurosurgery, Theoretic Principles, Art of Surgical Techniques. Berlin: Springer, 1998, pp 453-491

29. Rickham PP: A ventriculostomy reservoir. BMJ 2:173, 1964

30. Sells CJ, Shurtleff DB: Cerebrospinal fluid shunts. West J Med 127:93-98, 1977

31. Sivaganesan A, Krishnamurthy R, Sahni D, Viswanathan C: Neuroimaging of ventriculoperitoneal shunt complications in children. Pediatr Radiol 42:1029-1046, 2012
32. Sood S, Canady AI, Ham SD: Evaluation of shunt malfunction using shunt site reservoir. Pediatr Neurosurg 32:180186,2000

33. Sood S, Kim S, Ham SD, Canady AI, Greninger N: Useful components of the shunt tap test for evaluation of shunt malfunction. Childs Nerv Syst 9:157-162, 1993

34. Tschan CA, Antes S, Huthmann A, Vulcu S, Oertel J, Wagner W: Overcoming CSF overdrainage with the adjustable gravitational valve proSA. Acta Neurochir (Wien) 156:767-776, 2014

35. Vassilyadi M, Tataryn ZL, Matzinger MA, Briggs V, Ventureyra EC: Radioisotope shuntograms at the Children's Hospital of Eastern Ontario. Childs Nerv Syst 22:43-49, 2006

\section{Disclosures}

Drs. Schlosser and Zeiner have no conflicts of interest to disclose. Mr. Miethke is the founder of the Christoph Miethke GmbH \& Co. KG, and Dr. Crawack and Mr. Knitter are employees of this company. Dr. Sprung was supported by Aesculap for delivering presentations at scientific meetings, but had no financial interest in the products discussed in the present article.

\section{Author Contributions}

Conception and design: all authors. Acquisition of data: all authors. Analysis and interpretation of data: Schlosser, Crawack, Zeiner. Drafting the article: Schlosser, Miethke, Knitter. Critically revising the article: Schlosser, Miethke, Zeiner. Reviewed submitted version of manuscript: Schlosser. Approved the final version of the manuscript on behalf of all authors: Schlosser. Statistical analysis: Schlosser, Miethke, Knitter. Administrative/technical/ material support: Schlosser, Sprung. Study supervision: Schlosser, Sprung.

\section{Correspondence}

Hans-Georg Schlosser, Gutachten NWP, Seestraße 13, Berlin 13353, Germany. email: hans-georg.schlosser@charite.de. 